\title{
Shake-table tests of a reinforced concrete frame designed following modern codes: seismic performance and damage evaluation
}

\author{
Amadeo Benavent-Climent
}

David Escolano-Margarit

Leandro Morillas

This paper presents shake-table tests conducted on a two-fifths-scale reinforced concrete frame representing a conventional construction design under current building code provisions in the Mediterranean area. The structure was subjected to a sequence of dynamic tests including free vibrations and four seismic simulations in which a historical ground motion record was scaled to levels of increasing intensity until collapse. Each seismic simulation was associated with a different level of seismic hazard, representing very frequent, frequent, rare and very rare earthquakes. The structure remained basically undamaged and within the inter-story drift limits of the 'immediate occupancy' performance level for the very frequent and frequent earthquakes. For the rare earthquake, the specimen sustained significant damage with chord rotations of up to $28 \%$ of its ultimate capacity and approached the upper bound limit of inter-story drift associated with 'life safety'. The specimen collapsed at the beginning of the 'very rare' seismic simulation. Besides summarizing the experimental program, this paper evaluates the damage quantitatively at the global and local levels in terms of chord rotation and other damage indexes, together with the energy dissipation demands for each level of seismic hazard. Further, the ratios of column-to-beam moment capacity recommended by Eurocode 8 and ACI-318 to guarantee the formation of a strong column-weak beam mechanism are examined.

\section{INTRODUCTION AND RESEARCH SIGNIFICANCE}

One of the most common seismic force-resisting systems for building structures is the reinforced concrete (RC) frame. Following the paradigm of performance-based design, modern seismic codes establish seismic performance levels (SPL) that the structure must satisfy under different seismic hazard levels (SHLs). For SHLs associated with rare or very rare earthquakes (i.e., with return periods $P_{r}$ of the order of about 475 and 2000 years, respectively), the RC frame is allowed to dissipate energy through plastic deformations (i.e., undergoing structural damage) at special regions called plastic hinges by developing a stable plastic 'strong column-weak beam' mechanism. To this end, brittle failures must be prevented at the locations where plastic hinges are expected, by applying capacity design criteria. Although the frame is allowed to enter into the nonlinear range in the case of severe ground motions, common seismic design procedures are aimed at converting the complicated nonlinear dynamic behavior of the structure into an equivalent linear problem. This simplification is accomplished by the use of force reduction factors that depend on the inelastic 
response characteristics of the structural system and that rely strongly on the formation of the aforementioned strong column-weak beam mechanism.

There is a need to assess the inelastic response characteristics and performance of typical structures designed in view of provisions established by current seismic codes and to verify the adequacy of these provisions to meet the design performance objectives [1] under prescribed SHLs. Of paramount importance among these provisions is the ratio of the moment capacity of columns to beams framing into a joint, to assure the formation of a strong column-weak beam mechanism. It is also important to quantify the level of damage expected in a structure in each scenario of seismic hazard, not only in terms of maximum deformations (i.e., maximum chord rotation or inter-story drift) but also in terms of cumulative damage (i.e., dissipated energy). Progress in all these aspects calls for laboratory data and experimental evidence, and the best source for such information is the dynamic shake-table test. Shaking table tests reproduce in a most realistic way the seismic demands on structures subjected to ground motions, particularly within the nonlinear range and include cumulative damage effects. The behavior of real structures can be sensitive to rate of loading effects hardly captured with numerical models. Strain rate effects can modify the nominal resistance of the structural members and alter the intended hierarchy of strengths that guarantee the formation of a strong column-weak beam mechanism. Furthermore, a computationally effective modeling of the hysteretic behavior of $\mathrm{RC}$ elements requires introducing many simplifications (regarding the pinching effects, the strength and stiffness degradation, etc.) that may condition the actual response of the structure. The use of such analytical models entails calibration and verification through experimental data.

The general objective of this study is to assess experimentally, through shake-table tests, the seismic performance of RC frames with ductile reinforcement details designed according to modern codes. The study focuses on the quantitative evaluation of damage (in terms of maximum deformation, dissipated energy, chord rotations and damage indexes) imparted to the structure under each SHL, examining the ratio of moment capacity of columns to beams framing into a joint to guarantee the formation of a strong column-weak beam mechanism. To this end, shake-table tests of a partial structural model were conducted in the Laboratory of Dynamics of Structures of the University of Granada. The specimen was a two-fifths-scale model that represents a portion of a prototype building typical of conventional RC frame structures with regular and symmetric configuration, designed in view of current seismic codes in the Mediterranean area. The specimen was subjected to four seismic simulations of increasing intensity until collapse. The test results provide a quantitative evaluation of the global and local damage and energy dissipation demands for each SHL.

\section{PROTOTYPE STRUCTURE AND TEST SPECIMEN}

\subsection{Design of the prototype structure}

The three-story and three-bay RC moment-resisting frame shown in Figure 1 is considered as the prototype structure in this study. The structure is representative of existing modern buildings in the Mediterranean area. It is designed with the limit state design method considering gravity loads (dead loads of $3.22 \mathrm{kN} / \mathrm{m}^{2}$ for floors and $2.95 \mathrm{kN} / \mathrm{m}^{2}$ for the roof; and live loads of $2 \mathrm{kN} / \mathrm{m}^{2}$ for floors and $1 \mathrm{kN} / \mathrm{m}^{2}$ for the roof) and lateral seismic loading following the provisions of the current Spanish seismic code NCSE-02 [2]. The prototype building is assumed to be located in Granada (Spain), where the design ground acceleration (associated with a design earthquake of $P_{r}=500$ years), $a_{b}$, is $a_{b}=0.23 \mathrm{~g}$ ( $\mathrm{g}$ is the gravity acceleration). The concrete compressive strength $f_{c}$ assumed in the calculations was $f_{c}=25 \mathrm{MPa}$, and the yield strength for the steel was $f_{y}=500 \mathrm{MPa}$. The floor system consisted of one-way joists spaced $80 \mathrm{~cm}$ supported by the main beams (joist-band floor system). In turn, the one-way joists supported a thin concrete slab $6 \mathrm{~cm}$ thick. The cross section of the RC columns measured $40 \times 40 \mathrm{~cm}^{2}$. The section of the main beams that supported the joist was $30 \times 40 \mathrm{~cm}^{2}$; the cross section of the beams perpendicular to the main beams was $25 \times 35 \mathrm{~cm}^{2}$. Ductile reinforcement details and capacity design criteria were used so that the frame would develop a ductile strong column-weak beam plastic mechanism under lateral loads. The behavior factor $q$ 

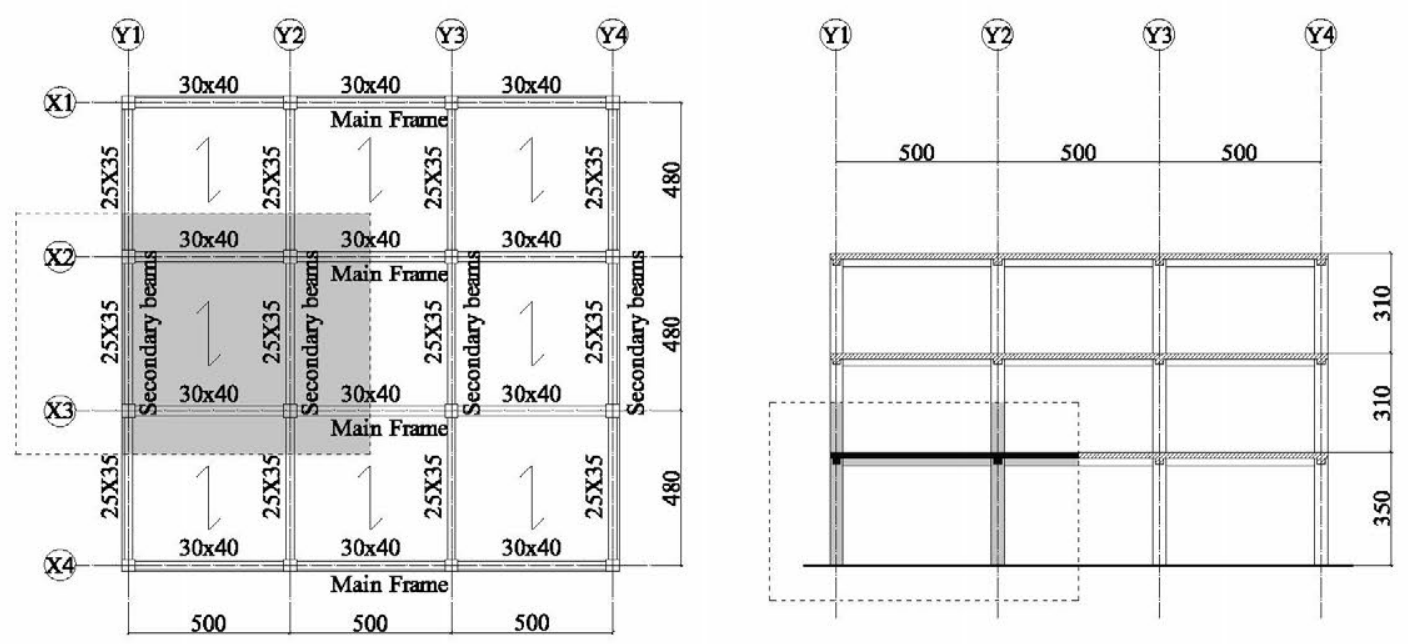

Test substructure

Figure 1. Prototype structure.

adopted for the seismic design was $q=3.0$, and the resulting base shear force coefficient of the prototype structure was 0.22 . According to the Spanish code, the behavior factor of $q=3$ corresponds to a full ductile structure that forms a strong column-weak beam mechanism under lateral loading and satisfies several requirements such as minimum amount of longitudinal reinforcement, maximum spacing of stirrups, and so on. The required strength of columns so that the structure developed the weak beam-strong column plastic mechanism shown in Figure 2 was based on the following considerations: (i) an inverted triangle distribution of lateral loads was adopted; (ii) the plastic hinges at beam ends (with symbol $\bullet$ in Figure 2) are concentrated at a distance $d_{r}=0.5 h_{c}+h_{b}$, where $h_{c}$ and $h_{b}$ are the depth of the column and of the beam, respectively; and (iii) the ultimate bending capacity of beams at plastic hinge regions, $M_{u b}$, was determined assuming that the actual yield stress was $1.25 f_{y}$. Capacity design was also applied at the plastic hinge level to prevent shear failure before the members reached their ultimate flexural capacity.

\subsection{Design and fabrication of the test specimen}

From the prototype, a partial structural model was separated from the original prototype by cutting through points of nominal zero bending moment under lateral loads. These lines are plotted with dots in Figure 1. The partial structural model has the height of one story and a half, and the width of one bay and a half in the direction of the main beams (i.e., those supporting the gravity loading). The test specimen was defined by applying scale factors of $\lambda_{L}=2 / 5$ for length, $\lambda_{a}=1$ for acceleration and $\lambda_{\sigma}=1$ for stress. Scale factors for the rest of the physical quantities were set to satisfy similitude

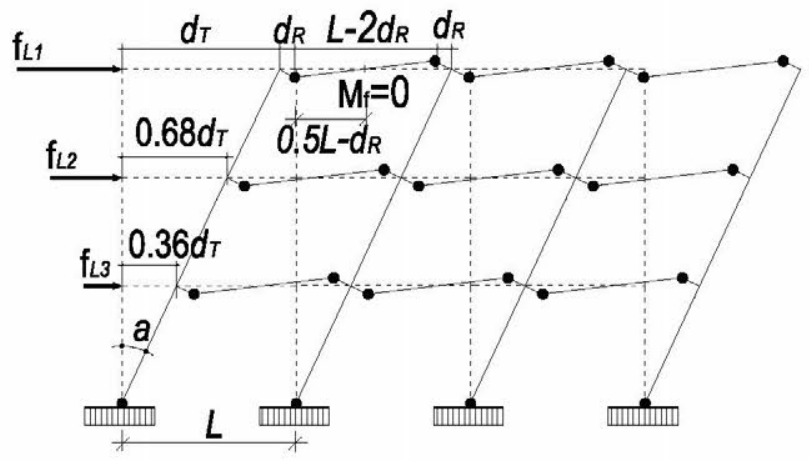

Figure 2. Plastic mechanism at global level. 
requirement [3]. Figures 3 and 4 show the geometry and reinforcing details of the two identical main frames that formed the test specimen. The two frames were connected by the following: (i) the joists and the thin slab reinforced with a steel mesh; and (ii) the perpendicular beams (secondary beams). Coupon tension tests were conducted on samples of reinforcing bars from each batch and size, giving a yield stress of $551 \mathrm{MPa}$ for the longitudinal reinforcement and $636 \mathrm{MPa}$ for the stirrups. Compression tests were conducted on normalized concrete cylinders on the $28^{\text {th }}$ day and the day of the tests, giving 35 and $41 \mathrm{MPa}$, respectively. The concrete strength of the test specimen was somewhat higher than assumed in the design of the prototype, probably due to the chemical admixtures used to make the concrete more fluid and facilitate the casting. This concrete overstrength was not considered in the design of the prototype, although it was taken into account when processing the experimental data. The ratio $s / d_{b}$ of the transversal reinforcement spacing $s$ to the diameter of the longitudinal bar $d_{b}$, at the beam critical sections was 5.7 (for the average value of the two diameters used as beam longitudinal reinforcement $d_{b}=8 \mathrm{~mm}$ and $d_{b}=6 \mathrm{~mm}$ ). The ratio $s / d_{b}$ at column critical sections was $s / d_{b}=5$. The area of longitudinal reinforcement $A_{s t}$ to the gross section $A_{g}$ of the columns was $A_{s l} / A_{g}=0.016$, and $A_{s l} / A_{g}=0.032$ in the regions were column bars where lap spliced.

\section{TEST SETUP, INSTRUMENTATION AND SEISMIC SIMULATIONS}

\subsection{Test setup and instrumentation}

The specimen was placed on the uniaxial MTS $3 \times 3 \mathrm{~m}^{2}$ shake-table of the University of Granada (Spain) as shown in Figures 5 and 6. The structure was oriented so that the direction of the uniaxial movement of the shake-table coincided with that of the main beams. To represent the gravity loads acting on the floors and to satisfy similitude requirements between prototype and test model, steel blocks were attached at the top the RC slab and at the top of half columns of the second story, as shown in Figure 5 (added weight). To reproduce the boundary conditions (i.e., zero bending

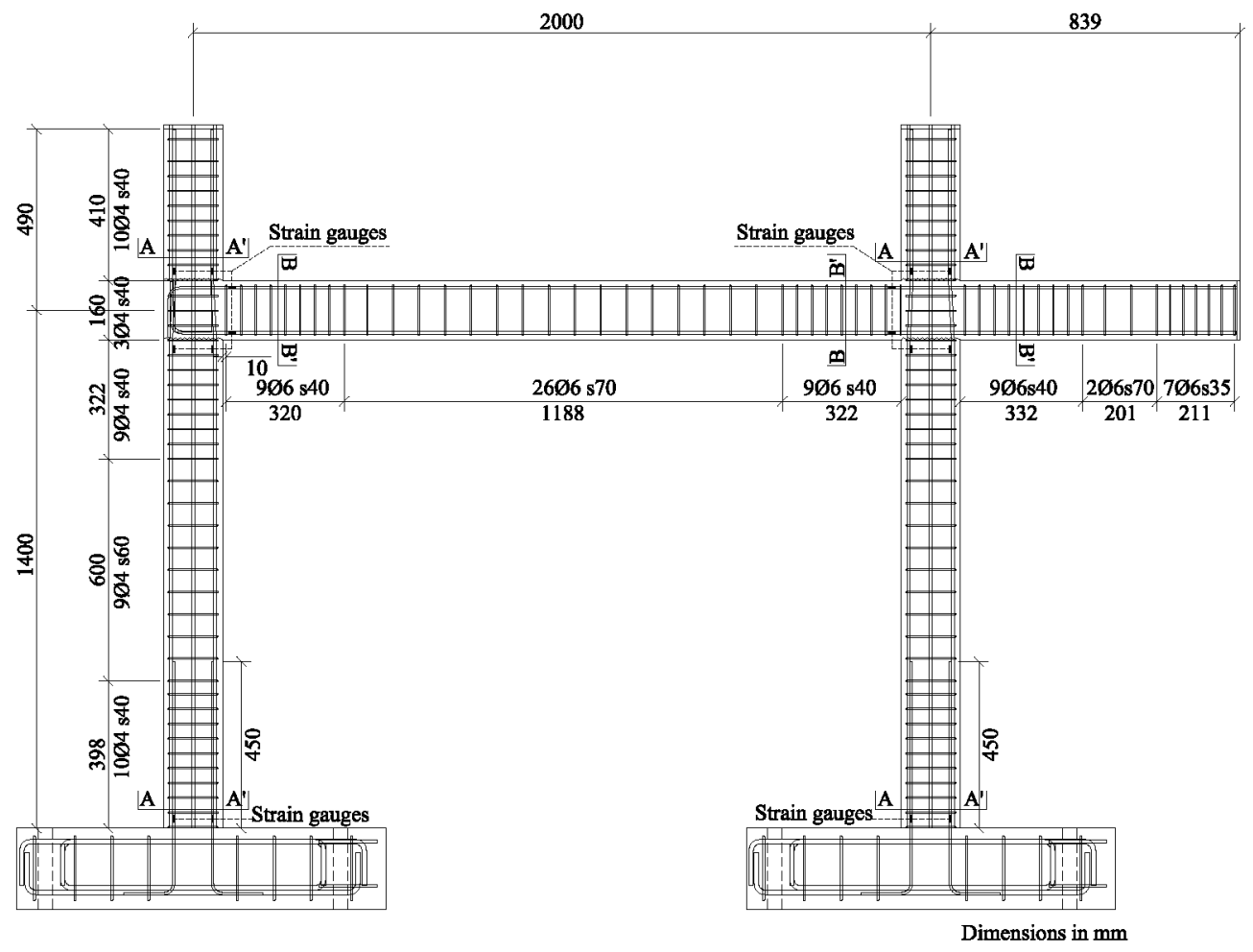

Figure 3. Test specimen. 


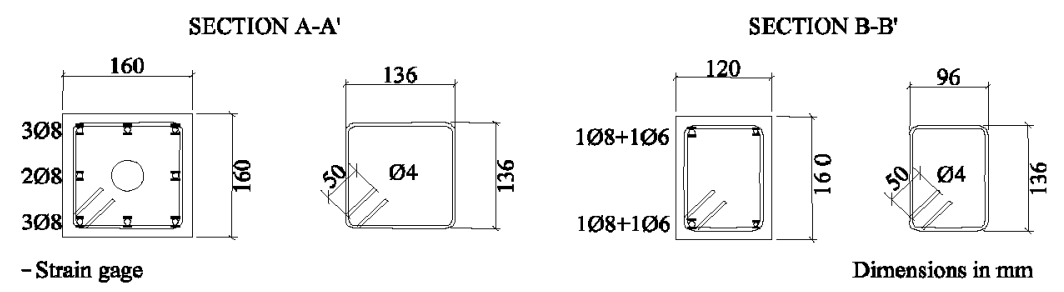

Figure 4. Reinforcing details of the reinforced concrete sections and location of strain gages.

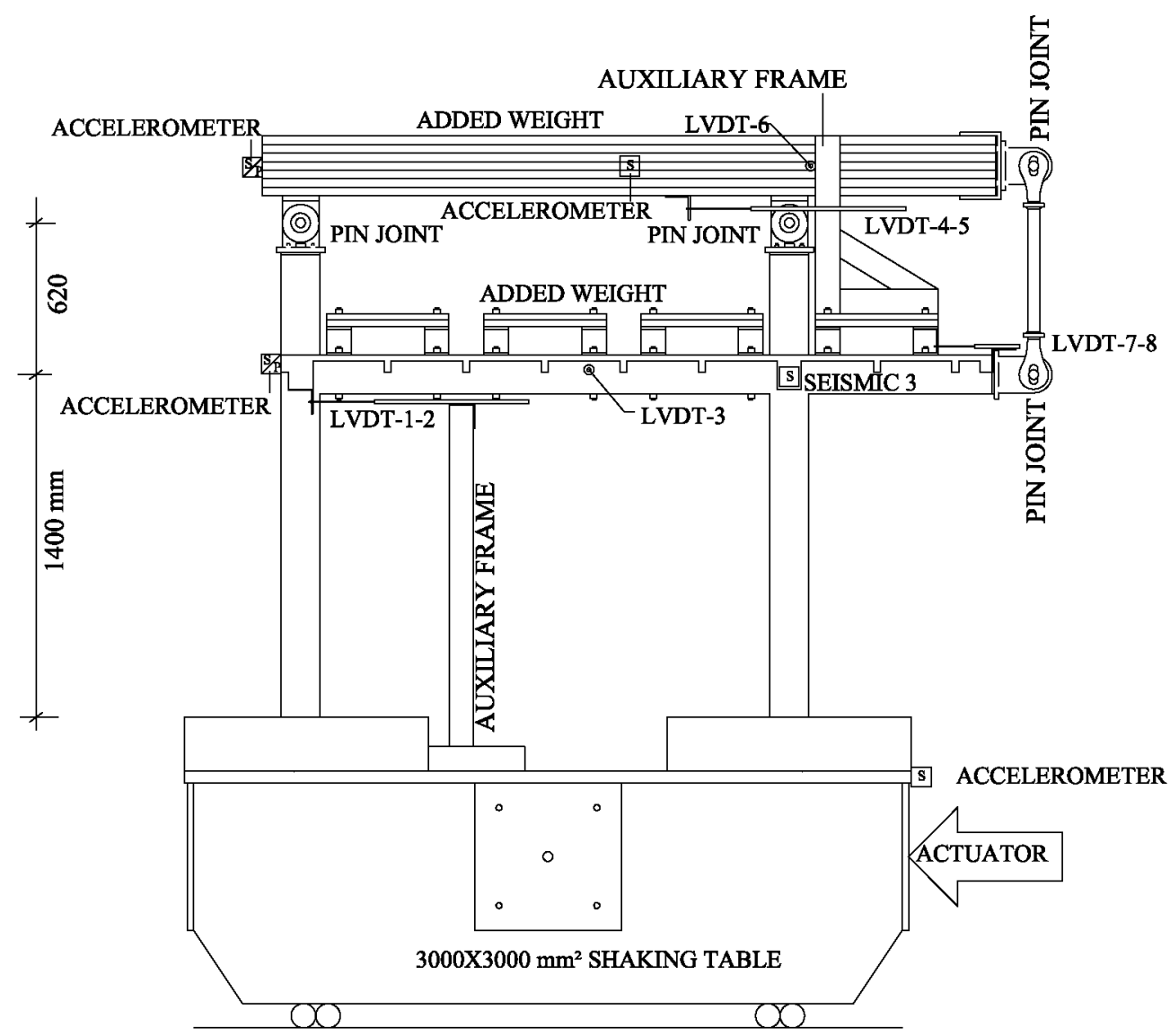

Figure 5. Test setup and instrumentation.

moment) of the substructure when the overall prototype building is subjected to lateral forces, pin joint connections were used at the top of the half-columns in the second story and at the ends of the halfbeams of the first floor. The restriction against vertical movements of the ends of the half-beams of the first floor was accomplished by means of pin-ended steel bars that connected the end of the beams with the steel plates (added weight) located on the top of the specimen, which have very large flexural stiffness in comparison with that of the RC frame. When the shake-table was accelerated, the inertial force generated in these steel blocks dynamically loaded the test model. The total mass of the test specimen (including the additional masses) was $10,070 \mathrm{~kg}$. It is worth noting that the purpose of the experiments was to investigate the behavior of the test specimen under earthquake-type dynamic loading, not to reproduce the particular response that the partial structural model would experience inside the overall frame under a particular ground motion, which is influenced by dynamic interactions with the upper part of the structure. The specimen was instrumented with 192 strain gages, 10 uniaxial accelerometers and 9 displacement transducers (linear variable differential transformers). Strain gages were attached to the surface of longitudinal 


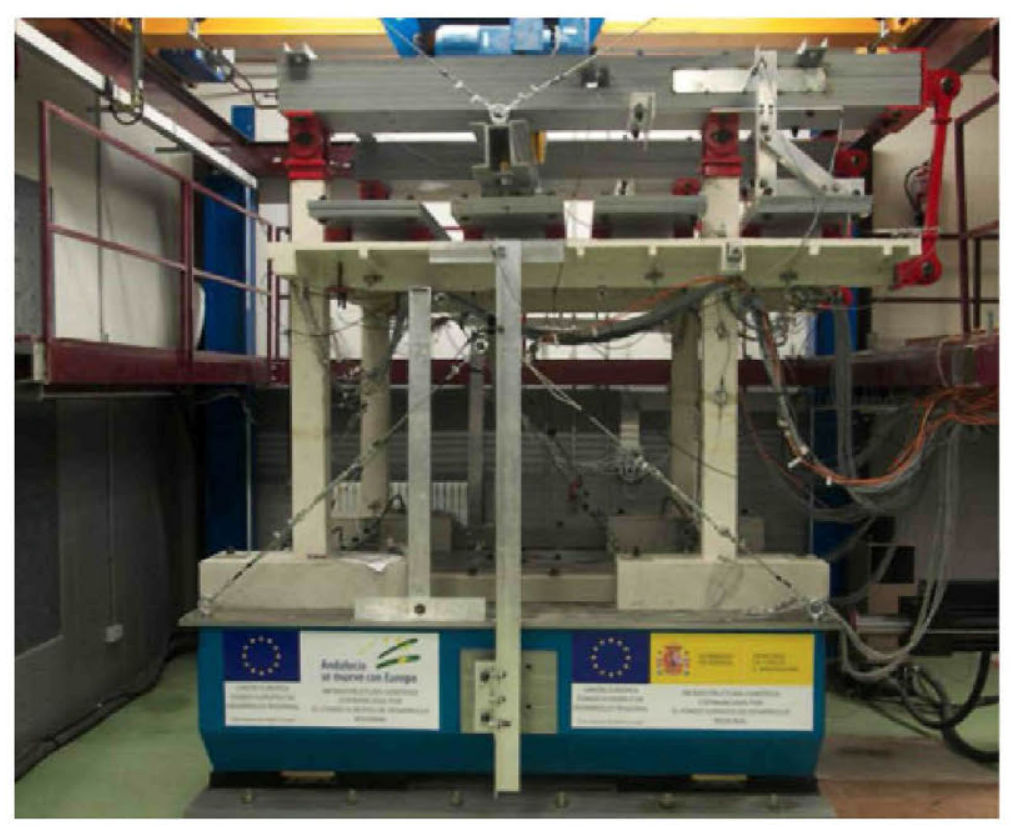

Figure 6. General overview of the tests.

reinforcement when construction was in progress; they were located, as shown in Figures 3 and 4, at column and beam ends. The displacement transducers measured the in-plane translations and the inter-story drifts in the direction (Figure 5) of the seismic loading. Data were acquired continuously with a scan frequency of $200 \mathrm{~Hz}$. Five video cameras recorded the experiments, four of them focusing on column bases, beam ends and beam-column joints.

\subsection{Seismic simulations}

The specimen was subjected to dynamic tests that consisted of four seismic simulations referred to as C50, C100, C200 and C300 herein, in which the shake-table reproduced the ground motion recorded at Calitri during the Campania-Lucania (1980) earthquake, respectively scaled in time by the scaling factor $\lambda_{\mathrm{t}}=\sqrt{\lambda_{L} / \lambda_{a}}=0.63$ and in amplitude to $50 \%, 100 \%, 200 \%$ and $300 \%$. Their corresponding peak ground accelerations, PGAs, were $0.08,0.16,0.31$ and $0.47 \mathrm{~g}$, respectively. Each PGA represents a different SHL at the site (Granada) that will be referred to hereafter as SHL-1, SHL-2, SHL-3 and SHL-4 respectively. SHL-1 represents a 'very frequent' earthquake, SHL-2 a 'frequent' earthquake, SHL-3 a 'rare' earthquake, and SHL-4 a 'very rare' or the 'maximum considered' earthquake. The SHLs can respectively be associated with $P_{r}$ of 17, 97, 500 and 1435 years. The relation between $P_{r}$ and PGA was obtained from the Spanish seismic code NCSE-02 [2] on the basis that: (i) the basic acceleration $a_{b, P r}$ for a given $P_{r}$ is $a_{b, P r}=a_{b}\left(P_{r} / 500\right)^{0.4}$; and (ii) the building is of ordinary importance, and it is located on soft soil (type IV). According to NCSE-02, for this type of soil, PGA $=1.34 a_{b, P r}$. Free vibration tests were performed before and after each simulation.

\section{TEST RESULTS AND INTERPRETATION}

\subsection{Dynamic characterization}

The third and fourth columns of Table I show the fundamental period $T_{1}$ and the damping ratio $\xi$ obtained from the free vibration tests conducted before and after each seismic simulation. $T_{1}$ was calculated by averaging the time between response peaks for several cycles and dividing by the number of cycles; $\xi$ was determined using the logarithmic decrement method. As anticipated, $T_{1}$ and $\xi$ increase with the intensity of the table motion, reflecting increasing levels of damage. Until 
Table I. Overall response parameters of the specimen.

\begin{tabular}{|c|c|c|c|c|c|c|c|c|c|c|c|c|c|c|c|}
\hline \multirow[b]{2}{*}{ Seismic simulation } & \multirow[b]{2}{*}{ SHL } & \multirow[b]{2}{*}{$T_{1}(\mathrm{~s})$} & \multirow[b]{2}{*}{$\xi(\%)$} & \multicolumn{3}{|c|}{ Story 1} & \multicolumn{3}{|c|}{ Story 2} & \multicolumn{2}{|c|}{ Top } & \multirow[b]{2}{*}{ SPL } & \multirow[b]{2}{*}{ SEAOC ID $(\%)$} & \multirow[b]{2}{*}{ ATC ID $(\%)$} & \multirow[b]{2}{*}{ FEMA ID $(\%$} \\
\hline & & & & $\ddot{u}_{\max }^{t}(\mathrm{~g})$ & ID $(\%)$ & $\mathrm{ID}_{\mathrm{r}}(\%)$ & $\ddot{u}_{\max }^{t}(\mathrm{~g})$ & ID $(\%)$ & $\mathrm{ID}_{\mathrm{r}}(\%)$ & ID $(\%)$ & $\mathrm{ID}_{\mathrm{r}}(\%)$ & & & & \\
\hline Prior test & & 0.31 & 2.7 & & & & & & & & & & & & \\
\hline C50 (end) & SHL-1 & 0.31 & 2.7 & 0.13 & 0.24 & 0.00 & 0.18 & 0.20 & 0.00 & 0.23 & 0.00 & $\mathrm{IO}$ & $0.2-0.5$ & $<1$ & $<1$ \\
\hline C100 (end) & SHL-2 & 0.32 & 3.8 & 0.28 & 0.50 & 0.00 & 0.33 & 0.42 & 0.00 & 0.45 & 0.00 & LS & $0.5-1.5$ & $1-2$ & $1-2$ \\
\hline C200 (end) & SHL-3 & 0.54 & 9.7 & 0.40 & 1.19 & 0.04 & 0.56 & 0.94 & 0.03 & 1.11 & 0.00 & LS & $0.5-1.5$ & $1-2$ & $1-2$ \\
\hline $\mathrm{C} 300^{\mathrm{a}}$ & SHL-4 & - & - & - & 4.08 & - & - & 4.03 & - & 4.06 & - & $\mathrm{C}$ & $>2.5$ & $>0.33 V_{i} / P_{i}$ & $>4$ \\
\hline $\mathrm{C} 300$ (end) & SHL-4 & - & - & - & 7.57 & 2.60 & & 8.09 & 4.09 & 7.66 & 3.06 & $\mathrm{C}$ & $>2.5$ & $>0.33 V_{i} / P_{i}$ & $>4$ \\
\hline
\end{tabular}

SHL, seismic hazard level; ID, identification; SPL, seismic performance level; IO, immediate occupancy; LS, life safety; C, collapse.

${ }^{a}$ At the instant of collapse; $V_{i}$, total lateral shear force in story $i ; P_{i}$, total gravity load in story $i$. 
seismic simulation $\mathrm{C} 200, T_{1}$ and $\xi$ remained basically unchanged, indicating an undamaged structure that kept its initial lateral stiffness. After seismic simulation C200, the period $T_{1}$ enlarged by about $70 \%$ and $\xi$ about $40 \%$, which reflects the occurrence of plastic deformations on the structure (damage) and a drop in the lateral stiffness of up to about $35 \%\left(=1000.32 / 0.54^{2}\right)$ of the initial value, as discussed later.

\subsection{Overall response}

For convenience in the forthcoming discussions, the specimen is modeled as follows. Beams and columns of each of the two frames that constitute the specimen are idealized with macro models consisting of a linear elastic member connecting two plastic hinges at the ends that concentrate the inelastic flexural deformations, as shown in Figure 7. Each plastic hinge is labeled with an identification number $k$.

The floor diaphragm with the added weight and the added weight put on the top of the columns can be assumed to behave as two rigid blocks, and they are idealized as two concentrated masses $m_{i}$ of 5910 and $4160 \mathrm{~kg}$, respectively. A degree of freedom consisting of the horizontal translation in the direction of shaking is assigned to each concentrated mass. With this model, the equation of dynamic equilibrium of the specimen is as follows:

$$
\mathbf{m} \ddot{\mathbf{u}}^{t}+\mathbf{c} \dot{\mathbf{u}}+\mathbf{F}_{\mathbf{S}}=\mathbf{0}
$$

where $\mathbf{m}$ is the diagonal mass matrix, $\ddot{\mathbf{u}}^{t}$ is the vector of absolute accelerations, $\mathbf{c}$ is the damping matrix, $\dot{\mathbf{u}}$ is the vector of relative velocities, and $\mathbf{F}_{\mathbf{S}}$ is the vector of restoring forces exerted by the structure. Because $\mathbf{m}$ is known and $\ddot{\mathbf{u}}^{t}$ was measured with the accelerometers, the total shear force $F_{I, B}$ exerted by the inertial forces $\mathbf{F}_{\mathbf{I}}=\mathbf{m} \ddot{\mathbf{u}}^{t}=-\left(\mathbf{c} \dot{\mathbf{u}}+\mathbf{F}_{\mathbf{S}}\right)$ at the base of the structure can be readily calculated as $F_{I, B}=\mathbf{F}_{\mathbf{I}}^{\mathbf{T}} \mathbf{1}$, where $\mathbf{1}$ is the unit vector. $F_{I, B}$ is plotted in Figure 8 against the displacement of the top of the structure $\delta_{T}$, for each seismic simulation. The results of simulation C300 are drawn until the instant of collapse; after this instant, many channels of the data acquisition system overflow. The $F_{I, B^{-}} \delta_{T}$ curve shown in Figure 8 indicates that up to collapse, the overall response of the specimen was characterized by a stable energy dissipation behavior with minor pinching in the loops.

In the instants of maximum lateral displacement, the velocity is zero, and therefore, the damping forces cù are null. At these instants, $F_{I, B}$ coincides with the base shear force carried by the structure $Q_{B}$. Values of $F_{I, B}$ when the velocity is zero and thus, $F_{I, B}=Q_{B}$ were calculated for each seismic simulation, and they are plotted in Figure 8 with open circles. These points define a polygonal curve that is drawn with bold lines, which can be interpreted as the 'capacity curve' of the structure. From this capacity curve, a yield base shear force, $Q_{B y}$, and a yield top displacement $\delta_{T}$ are defined for each domain of loading, giving $Q_{B y}{ }^{+}=36.4 \mathrm{kN}, \delta_{T}^{+}=11.7 \mathrm{~mm}, Q_{B y}{ }^{-}=43.7 \mathrm{kN}$, and $\delta_{T}^{-}=13 \mathrm{~mm}$. This capacity curve allows us to calculate the average base shear force coefficient, $\alpha_{B}=0.5(36.4+43.7) / 100.7=0.4$ and initial stiffness $K_{e}=(36.4+43.7) /(11.7+13)=3.24 \mathrm{kN} / \mathrm{mm}$. Comparing $\alpha_{B}$ with the base shear force coefficient used in the design (0.22), it is concluded that the structure has an overstrength of $0.4 / 0.22=1.8$. This value is about $40 \%$ larger than the overstrength specified by Eurocode 8 [4]. The initial fundamental period estimated with $K_{e}$ and the total mass of the specimen $(5910+4160=10070 \mathrm{~kg})$ is $0.35 \mathrm{~s}$, which is close to that obtained from vibration tests (Table I).
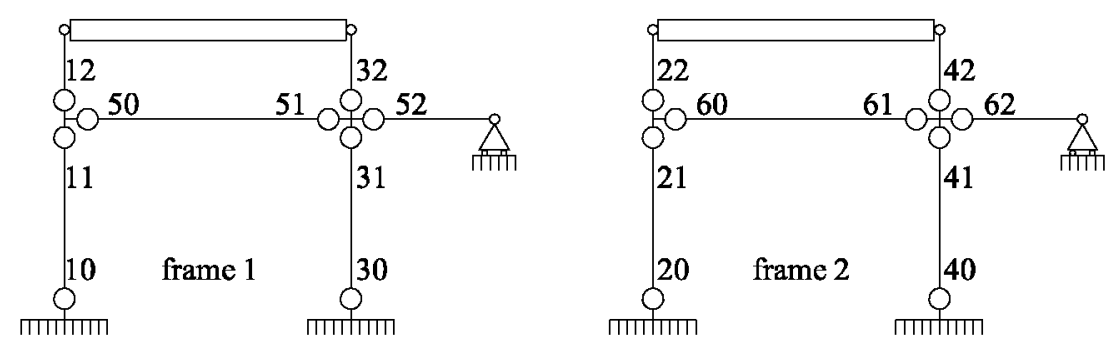

Figure 7. Idealization of the reinforced concrete frames in the direction of the seismic loading. 


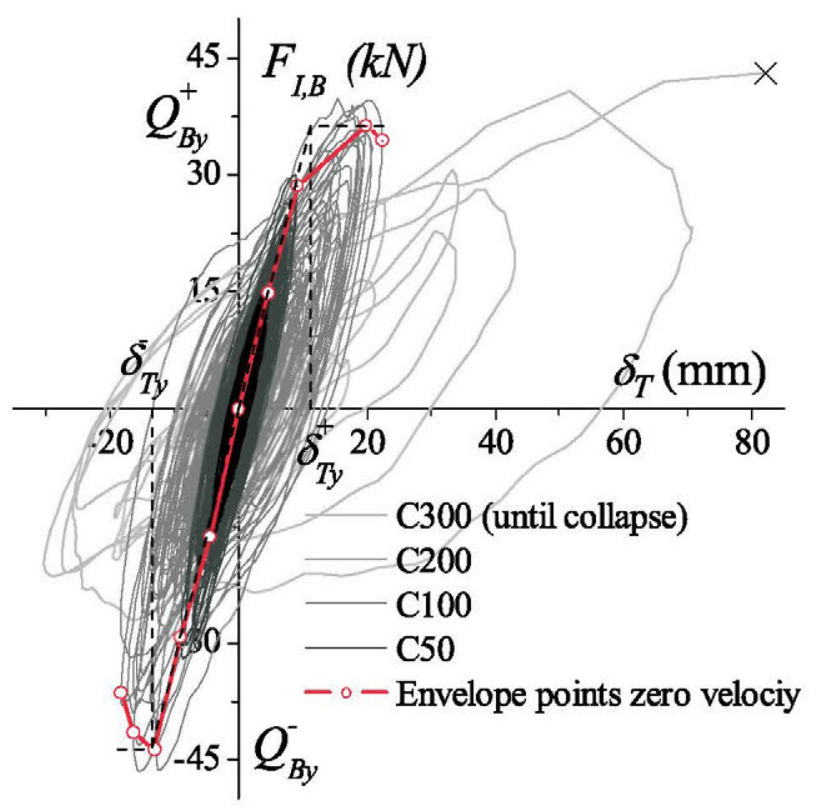

Figure 8. Base shear force due to inertial forces versus top displacement.

A more detailed examination of the overall response of the specimen after each seismic simulation is summarized in Tables I and II. For each seismic simulation, Table I shows in columns 5 to 10 the maximum response acceleration $\ddot{\mathbf{u}}^{t}{ }_{\text {max }}$, the maximum inter-story drift ID and the residual inter-story drift $\mathrm{ID}_{\mathrm{r}}$ of each story. Columns 11 and 12 show the maximum drift $\mathrm{ID}$ and the residual drift $\mathrm{ID}_{\mathrm{r}}$ relative to the base at the top of the specimen. In the case of simulation $\mathrm{C} 300$, there are two rows in Table I; the first one corresponds to the instant of collapse, as discussed later, and the second one to the end of the seismic simulation. Table II summarizes the maximum strains measured in the longitudinal bars located at the member end sections of the two RC frames. Each member end section is a potential plastic hinge under lateral loadings, and it is identified with the number shown in Figure 7. In Table II, the member end sections are grouped according to their position in the frames (base, interior beam-column connection and exterior beam-column connection). Several longitudinal reinforcing bars were instrumented at each member end section (Figures 3 and 4); Table II shows the maximum $\varepsilon_{\max }$, the average $\bar{\varepsilon}$ and the standard deviation $\sigma$ of the strains measured at each section. The strains corresponding to seismic simulation C300 are not included, because during this simulation most gages reached their maximum measurable strain and stopped functioning. The yield strain of the steel $\varepsilon_{y}$ was $2625 \mu \mathrm{m} / \mathrm{m}$.

The overall response of the tested structure is characterized by the formation of the expected strong column-weak beam mechanism, as indicated by the measurements of the strain gages, and by the fact that, for all seismic simulations, the inter-story drift ID reached very similar values in both stories. Plastic hinges developed basically at column bases and at beam ends, although some unexpected plastic strains (up to $1.4 \varepsilon_{y}$ ) were measured in one of the columns (sections 41 and 42 in Figure 7) when the structure was on the verge of collapse. The members exhibited ductile flexural failures; shear or axial failures were not observed. A detailed description of the performance under each SHL is presented in the succeeding discussion.

The seismic simulation C50 represented a low SHL for the building site, that is, a frequent earthquake expected to take place during the conventional working life of the building, therefore having a $P_{r}$ shorter than 50 years. After this level of seismic action, referred to as SHL-1, the specimen showed no visible damage. The strains in the reinforcing bars at the base of the columns remained below $0.7 \varepsilon_{y}$ and those at beams ends below $0.5 \varepsilon_{y}$. The minor increase of $0.01 \mathrm{~s}$ in $T_{I}$ shown in Table I can be attributed to the concrete microcracking. There was no residual inter-story drift or other permanent structural deformation. The overall damage in qualitative terms was therefore very light. The maximum inter-story drift ID reached $0.24 \%$ of story height. This ID is 


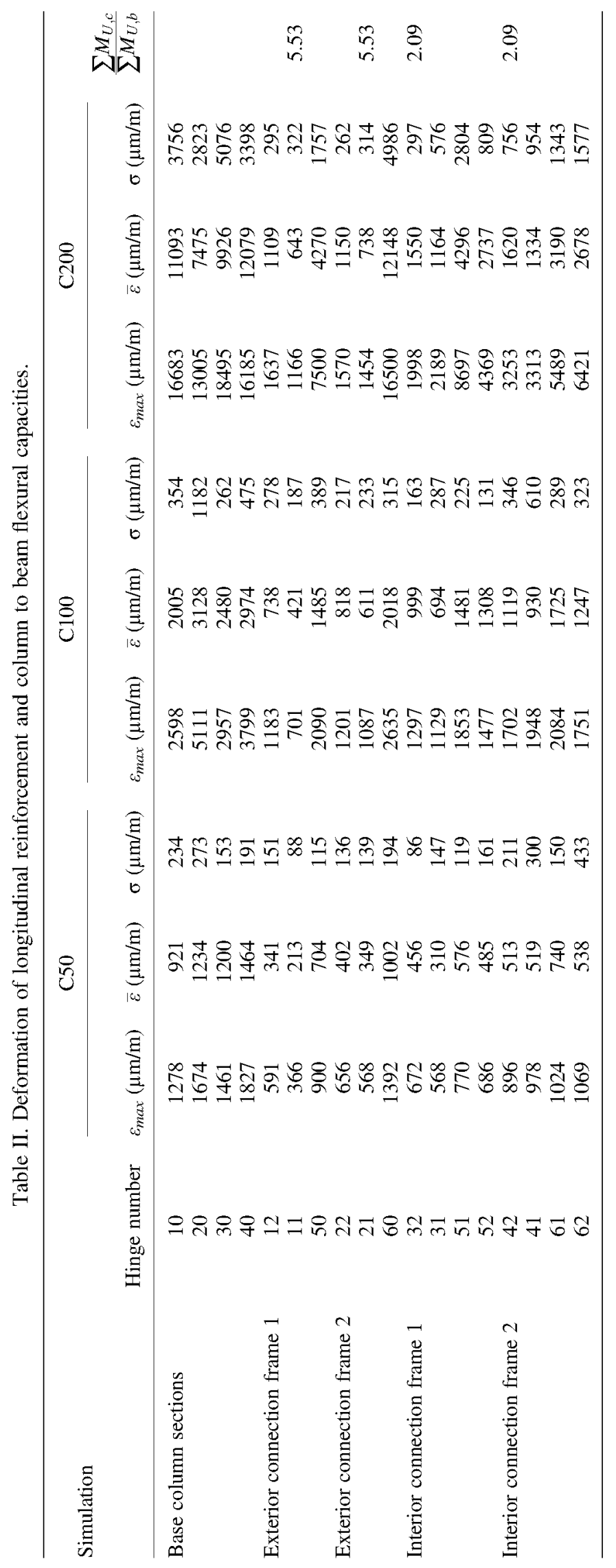


within the range $0.2 \leq \mathrm{ID}<0.5$ that Structural Engineers Association of California (SEAOC) [5] associates with the SPL of 'immediate occupancy' (IO). The SPL of IO corresponds to the SPL of 'damage limitation' (DL) in Eurocode 8 [4], which also limits the ID to $0.5 \%$ if the story has brittle nonstructural elements attached to the structure. For structures of ordinary importance, Eurocode 8 recommends pursuing the SPL of DL for a seismic action of $P_{r}=95$ years.

The seismic simulation $\mathrm{C} 100$ corresponds to a moderate level earthquake, that is, an 'occasional' earthquake with a $P_{r}$ between 75 and 200 years. During this level of seismic action, referred to as SHL-2, the longitudinal reinforcement at the base of the columns yielded, reaching strains up to about $2 \varepsilon_{y}$. The sections at the ends of the beams were on the brim of yielding, exhibiting strains on the longitudinal reinforcement very close or slightly above $\varepsilon_{y}$. The longitudinal reinforcement of the columns at sections other than the base approached the yield strain (up to $0.75 \varepsilon_{y}$ ). This was accompanied by some cracking. The permanent deformations were negligible. The structure was basically undamaged and retained its integrity, full vertical load-bearing capacity, and sufficient residual lateral strength and stiffness to sustain additional shakings. The maximum ID was $0.5 \%$ of story height. According to SEAOC [5], this ID is the boundary between the SPL of IO $(0.2 \leq \mathrm{ID}<0.5)$ and 'life safety' (LS) $(0.5 \leq \mathrm{ID}<1.5)$. The value of $P_{r}$ for the seismic simulation C100 (97 years) is very close to the mean return period of seismic action (95 years) under which Eurocode 8 recommends that the structure should respond in the SPL of DL, which is characterized by ID $0.5 \%$. From this point of view, it can be said that the specimen behaved on the limit of what Eurocode 8 recommends.

The seismic simulation $\mathrm{C} 200$ represents a strong ground motion (the design earthquake) at the building site, that is, a rare earthquake with a $P_{r}$ of about 500 years, and is referred to as SHL-3. A visual inspection of the specimen after this test revealed significant damage (SD; extensive flexural cracks at the base of the columns and at beam ends), although the gravity-load bearing system kept functioning. Plastic hinges with ductile flexural yielding developed at the base of the columns and at beam ends. The maximum strains of the longitudinal reinforcement at the base of the columns ranged between $5 \varepsilon_{y}$ and $7 \varepsilon_{y}$, and those located at beam ends oscillated between $1.7 \varepsilon_{y}$ and $6.3 \varepsilon_{y}$. Concrete crushing was observed at the base of the columns. The frame developed a complete strong column-weak beam mechanism. Excepting in the sections at the base, columns remained basically elastic, although some slight inelastic excursion was measured in one column at hinges number 41 and 42 (Figure 7), where $\varepsilon$ exceeded the yield strain up to $1.4 \varepsilon_{y}$. Permanent deformation was very small $(0.04 \%$ of story height). The maximum ID was $1.19 \%$ of story height. According to SEAOC [5], this ID is close to the boundary between the SPLs of LS $(0.5 \leq \mathrm{ID}<1.5)$ and 'collapse prevention' (CP) $(1.5 \leq \mathrm{ID}<2.5)$. The SPL of LS and CP is the counterpart of the SPLs denominated 'SD' and 'near collapse' by Eurocode 8 .

The seismic simulation C300 represents a very rare or the maximum considered earthquake, with quoted values of the mean return period in the order of 1000-2500 years. Under this seismic action, referred to as SHL-4, the structure was very heavily damaged. The records of a video camera that focused on one of the beam ends showed that about $8 \mathrm{~s}$ after the onset of the movement of the shake-table, a flexural crack opened abruptly at the beam end, reaching a maximum width of about $3 \mathrm{~mm}$, which was accompanied by a sudden vertical slide of approximately $10 \mathrm{~mm}$ between the two sides of the flexural crack, as shown in Figure 9(a). Simultaneously, the inter-story drifts reached about four times the maximum values attained in previous simulations. This vertical slide, and the fact that the gages attached to the longitudinal reinforcement of this beam experienced a sudden increase in strain and stopped measuring, point to the exhaustion of the beam's 'ultimate' capacity. At this instant, the lateral drift at the top of the specimen (i.e., at the center of the pinned ends of the columns of the second story) was $4.06 \%$ of the total height $(2020 \mathrm{~mm})$. This is taken hereafter as the instant of collapse. At this same instant, severe concrete crashing was also observed at the column bases as shown in Figure 9(b). The test continued after this instant, and lateral drift reached about $8 \%$ of story height, whereas residual deformations amounted to about $4 \%$. This SPL clearly corresponds to a situation of collapse (C) according to SEAOC [5] (ID $>2.5 \%$ ). For the sake of completeness, Table I indicates the limiting values of the ID for each SPL according to ATC-40 [6] and FEMA-356 [7]. It is worth noting that Eurocode 8 [4] specifies in clause 5.5.3.1.2(3) the requirement to provide inclined reinforcement in two directions to prevent shear sliding failure. 

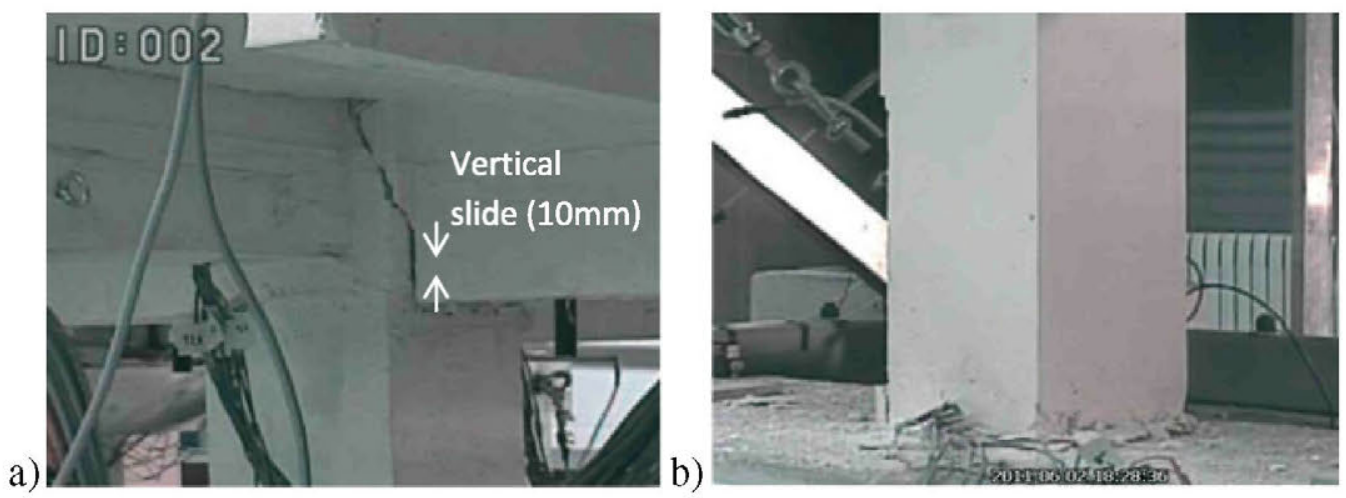

Figure 9. Damage at: (a) beam ends and (b) the base of columns during simulation C300.

Appling this clause to the prototype structure under investigation gives an area of required inclined reinforcement in each direction crossing the potential sliding plane of $11.1 \mathrm{~mm}^{2}$.

Figure 10 represents, in abscissa, the IDs and corresponding SPLs discussed earlier, and in ordinates the SHLs. The SPL denoted by O means 'operational' and describes a condition in which the facility has suffered practically no structural or nonstructural damage and can continue serving the original intention of its design. The 'performance objective' for structures of ordinary importance is to fulfill the relationship between SPL and SHL indicated by the area shaded with lines inclined $45^{\circ}$. The actual response of the tested frame is represented by the area shaded with lines inclined $-45^{\circ}$. It follows from Figure 10 that the performance of the tested structure in terms of ID is basically within acceptable limits for SHL-1, SHL-2 and SHL-3, yet just barely; but for SHL-4, the performance is outside the acceptable limits.

\subsection{Damage evaluation at global level}

The energy balance of the structure at any instant $t$ when it is subjected to a horizontal translational component of the ground motion is given by Eq. (2). Here, $E_{I}$ is the (relative) [8] energy input by the earthquake; $W_{\xi}$ is the energy dissipated by the inherent damping mechanism; $W_{p}$ is the hysteretic (plastic strain) energy; $W_{e s}$ is the elastic strain energy; and $W_{k}$ is the kinetic energy. The sum of the kinetic and the elastic strain energies constitutes the elastic vibrational energy $W_{e}\left(=W_{e s}+W_{k}\right)$. The energy input $E_{I}$ and the kinetic energy $W_{k}$ can be easily calculated by Eqs (3) and (4) from the masses $m_{i}$, their relative displacements $u_{i}$ and the acceleration on the shake-table $\ddot{u}_{g}$ measured during the tests. The hysteretic (plastic strain) energy $W_{p}$ and the elastic strain energy $W_{e s}$ can be estimated as explained in Section 4.4 later. Further, according to Eq. (2), the difference between the input energy and the elastic vibrational energy $W_{e}$, that is, $E_{I}-W_{e}=E_{I}-\left(W_{k}+W_{e s}\right)$, is equal to the total absorbed energy, that is, the sum of hysteretic and viscous energies, $W_{p}+W_{\xi}$. Figure 11(a) shows the histories

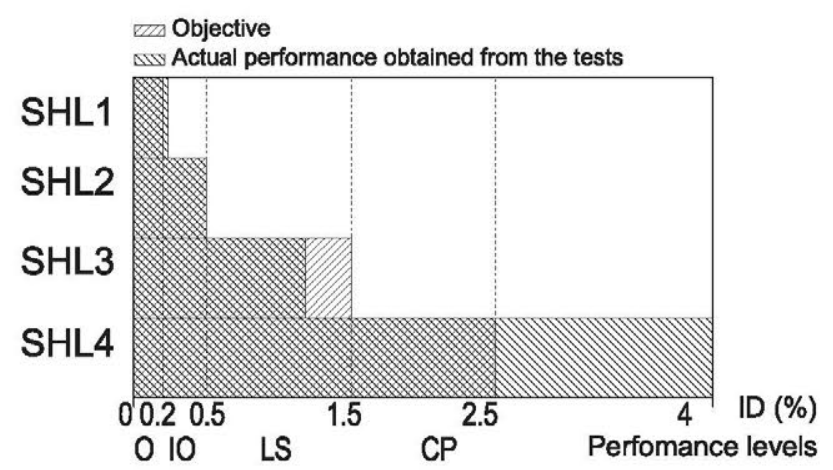

Figure 10. Comparison between performance objectives and tested behavior. 

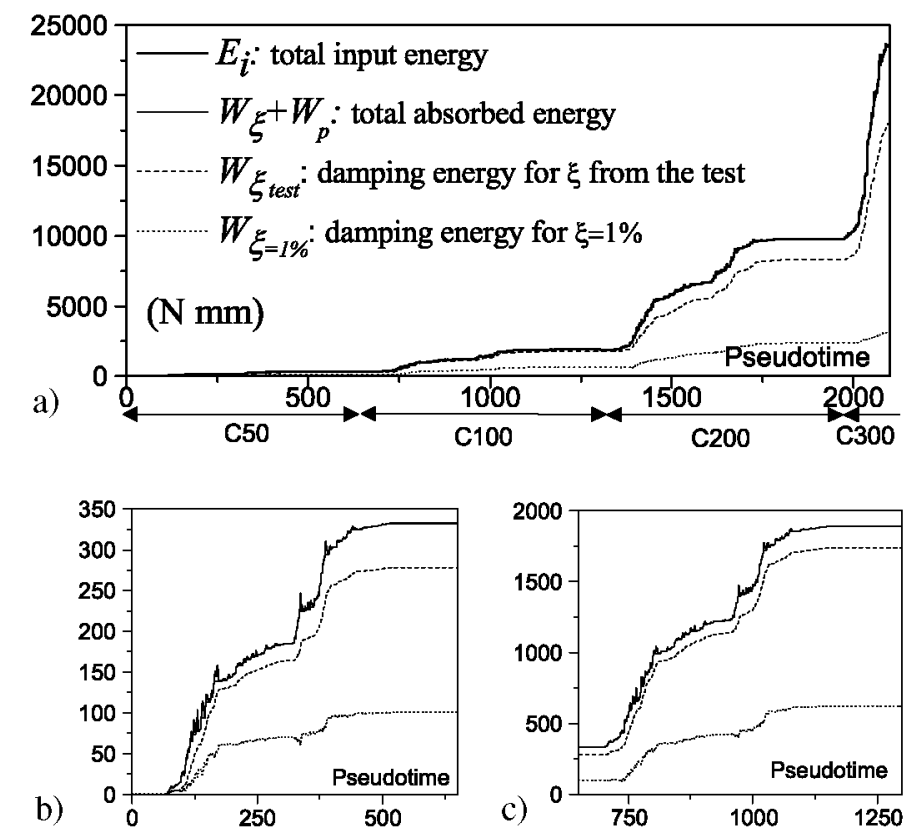

Figure 11. Histories of accumulated energy: (a) up to collapse; (b) for C50; and (c) for C100.

of input energy $E_{I}$ and the total absorbed energy $W_{p}+W_{\xi}$, accumulated in the successive seismic simulations from the beginning of simulation C50 until collapse. The amounts of energy input during seismic simulations C50 and C100 are much smaller than that of simulation C200; the energies for C50 are about one-fifth of those of $\mathrm{C} 100$ and the latter about one-fifth of $\mathrm{C} 200$. To better view the history of energies for simulation C50 and C100, a zoom of Figure 11(a) in the temporal range of these simulations is shown in Figure 11(b) and (c). In the case of simulation C300, it was not possible to calculate the energies beyond collapse due to the large displacements and deformations experienced by the structure, which caused overflow in the measurements of many channels of the data acquisition system.

$$
\begin{gathered}
E_{I}=W_{\xi}+W_{p}+W_{e s}+W_{k} \\
E_{I}=\sum_{i=1}^{2} \int_{0}^{t} m_{i} \ddot{u}_{g} \dot{u}_{i} d t \\
W_{k}=\frac{1}{2} \sum_{i=1}^{2} m_{i} \dot{u}_{i}^{2} d t \\
W_{\xi}^{t} \int_{0}^{t} \dot{\mathbf{u}}^{\mathbf{T}} \mathbf{C} \dot{\mathbf{u}} d t
\end{gathered}
$$

A portion of the total absorbed energy $W_{p}+W_{\xi}$ is dissipated by viscous damping, $W_{\xi}$. Yet, it is not possible to calculate $W_{\xi}$ with accuracy, because in a shake-table test, which goes deeply into the nonlinear range, it is hard to distinguish hysteretic from viscous damping. An attempt was nonetheless made to obtain a rough estimation of $W_{\xi}$ as follows. First, the tested structure was idealized as a two-dimensional model with two lumped masses. Second, the viscous damping of the structure was represented by the traditional Rayleigh damping matrix using the frequencies obtained for the first and second vibration modes from an eigenvalue analysis, and adopting the same 
damping ratio $\xi$ for both modes. Third, the history of velocities of each mass was calculated by deriving the history of displacements measured with the transducers during the tests, to arrive at the vector of relative velocity $\dot{\mathbf{u}}$. Finally, $W_{\xi}$ was estimated with Eq. (5). In this calculation, a key point is the value assumed for $\xi$. One approximation to estimate $W_{\xi}$ for a given seismic simulation is to use the damping ratios $\xi$ obtained from the free vibration test conducted at the end of previous seismic simulations, which are shown in Table I. These values of $\xi$ are larger than those used in studies that applied a similar approach for representing damping [9]. Martinelli and Filippou [9] predicted the nonlinear response of a full-scale seven-story RC structure tested on a shaking table under four successively input motions using a common damping ratio $\xi=1 \%$ for all seismic simulations and found that analytical results led to a good agreement between the measured and predicted response. For illustrative purposes, the history of $W_{\xi}$ estimated with the $\xi$ obtained from the free vibration test at the end of a previous seismic simulation is shown in Figure 11 with thin dash lines, whereas $W_{\xi}$ calculated with $\xi=1$ in all seismic simulations is shown in Figure 11 with thin dotted lines. Finally, for convenience $E_{I}$ can be normalized with respect to the total mass $\left(m_{1}+m_{2}\right)$ and expressed by equivalent velocity $V_{E}$ defined by

$$
V_{E}=\sqrt{2 E_{I} / \sum_{i=1}^{2} m_{i}}
$$

Table III summarizes the (accumulated) input energy $V_{E}$ from the onset of the tests up to the end of a given seismic simulation or to collapse. It is worth noting that the values $V_{E}$ are calculated for the specimen from the test results and that the specimen was scaled by the factors indicated in Section 2.2. To obtain the corresponding energies in the prototype (real) structure, $V_{E, p}$, the values must be divided by the scaling factor for velocity $\lambda_{v}=\lambda_{L} / \lambda_{t}=0.63$.

\subsection{Damage evaluation at local level}

The elastic and plastic strain energy absorbed/dissipated by a given plastic hinge $k$ of the structure during the cyclic loading, $W_{e s, k}+W_{p, k}$, is the sum of the energy dissipated by the concrete, $W_{C, k}$, and the energy dissipated by the longitudinal reinforcement, $W_{S, k}[10] . W_{S, k}$ was estimated from the data measured during the seismic simulations as follows. The history of strain in a given longitudinal rebar $r, \varepsilon_{S r}(t)$, was measured directly by the strain gages, whereas the corresponding stress $\sigma_{S r}(t)$ can be approximated from $\varepsilon_{S r}(t)$ using an energy conservative steel model that incorporates strainhardening and Bauschinger effects. Calling $A_{S r}$ the area of rebar $r$ and assuming a length $l_{p}$ for the plastic hinge, $W_{S, k}$ is

$$
W_{S, k}=\sum_{r=1}^{R} \int l_{p} A_{s r} \sigma_{s r} d \varepsilon_{s r}
$$

where the summation is extended to the $R$ steel longitudinal rebars of the cross section of the plastic hinge $k$. On the other hand, the energy dissipated by the concrete $W_{C, k}$ in a given plastic hinge $k$ is computed by applying the following procedure: (i) the depth $h$ of the cross section of the RC member is divided in $N$ parts (referred to as fibers), each fiber $j$ having a width $b$ and an area $b(h / N)$; (ii) the plane-remaining plane assumption is made and the strain $\varepsilon_{C j}(t)$ at a given fiber $j$ is estimated from the curvature measured with the strain gages on the steel rebars; (iii) the corresponding stress

Table III. Energies in terms of equivalent velocities.

\begin{tabular}{lcc}
\hline Cumulative values up to seismic simulation & Specimen $V_{E}(\mathrm{~cm} / \mathrm{s})$ & Prototype $V_{E, p}(\mathrm{~cm} / \mathrm{s})$ \\
\hline C50 & 26 & 41 \\
C100 & 62 & 98 \\
C200 & 140 & 222 \\
C300 (up to collapse) & 216 & 343 \\
\hline
\end{tabular}


$\sigma_{c j}(t)$ is approximated from $\varepsilon_{C j}(t)$ using a modified Kent and Park material model [11, 12] with linear loading and reloading paths and no tensile strength; and (iv) the energy $W_{C, k}$ is calculated by

$$
W_{C, k}=\sum_{j=1}^{N} \jmath_{l} b \frac{h}{N} \sigma_{C j} d \varepsilon_{C j}
$$

Among the several formulations proposed in the literature to determine $l_{p}$, in the former Eqs (7) and (8), the plastic hinge length was made equal to the element depth. The elastic and plastic strain energy absorbed/dissipated by a given plastic hinge $k$ is thus

$$
W_{e s, k}+W_{p, k}=W_{S, k}+W_{C, k}
$$

Further, $W_{p, k}$ can be estimated from $\left(W_{p, k}+W_{e s, k}\right)$ by removing from the latter the reversible elastic part. The total elastic and plastic strain energy absorbed/dissipated by the structure $W_{e s}+W_{p}$ is the sum of the contributions of the $p$ plastic hinges, that is,

$$
W_{e s}+W_{p}=\sum_{k=1}^{p}\left(W_{e s, k}+W_{p, k}\right)
$$

The energy absorbed/dissipated by the plastic hinges during each seismic simulation, as calculated with Eqs (7) and (8), was grouped and summed up as follows: energy absorbed/dissipated at the base of the columns (i.e., hinges number 10,20,30 and 40 in Figure 7), energy absorbed/dissipated at beam ends (i.e., hinges number 50, 51, 52, 60, 61, 62 in Figure 7), energy absorbed/dissipated at the upper ends of the columns of the first story (hinges number 11, 21, 31, 41 in Figure 7) and energy absorbed/dissipated at lower ends of the columns of the second story (hinges number 12, 22, 32, 42 in Figure 7). The total energy absorbed/dissipated by the hinges of each group is plotted in Figure 12(a). These energies accumulated in the successive seismic simulations, from the onset of
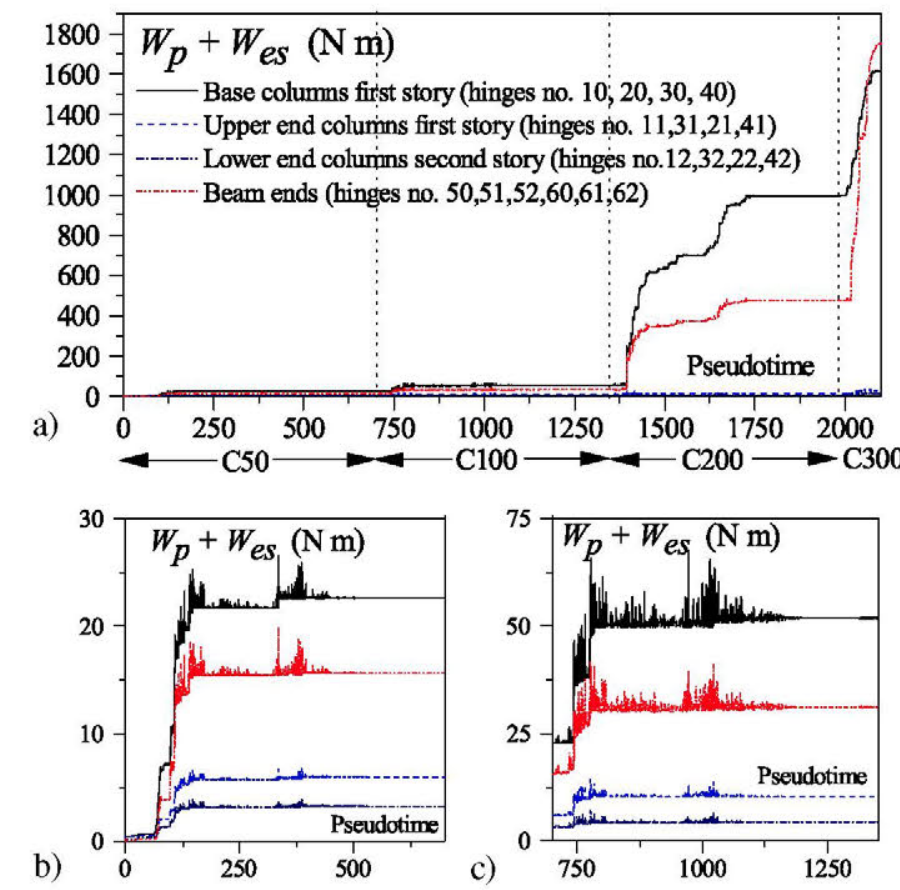

Figure 12. Energy absorbed/dissipated by hinges: (a) up to collapse; (b) C50; and (c) C100. 
simulation C50 until collapse during simulation C300. Because the amounts of energy input during seismic simulations $\mathrm{C} 50$ and $\mathrm{C} 100$ are much smaller than that of simulation $\mathrm{C} 200$, a zoom of Figure 12(a) in the temporal range of simulations C50 and C100 is shown in Figure 12(b) and (c), respectively. Given that the specimen developed a strong column-weak beam mechanism, the energy absorbed/dissipated by the upper ends of the columns of the first story and by the lower ends of the columns of the second story is small in comparison with that dissipated at the base of the columns and at beam ends. Until the end of seismic simulation C200, the energy absorbed/ dissipated at the base of the columns is from 1.5 to 2 times larger than that dissipated by the beams. However, when the specimen is on the brim of collapse (at the beginning of simulation C300), there is an abrupt increase of the energy dissipated at beam ends, whereas that dissipated at column bases increases only 1.6 times. The curves do not increase monotonically due to the presence of elastic strain energy; this effect is negligible in seismic simulation C200, because the amount of elastic strain energy is very small in comparison with the energy dissipated through plastic deformations. During seismic simulation C50, the main source of energy dissipation was the plastic deformation of concrete, because the longitudinal reinforcement did not yield. During seismic simulation C100, both concrete and longitudinal reinforcement dissipated energy by means of inelastic strains. Conversely, during seismic simulation C200, energy dissipated by concrete is negligible in comparison with that by steel.

The damage at the level of each individual hinge $k$ was estimated in terms of maximum chord rotation demand $\theta_{m}$ in relation to chord rotation at ultimate capacity $\theta_{u}$, that is, $\theta_{m} / \theta_{u}=\max \left\{\left|\theta_{m}{ }^{+} / \theta_{u}{ }^{+} \mathrm{I},\right| \theta_{m}{ }^{-} / \theta_{u}{ }^{-} \mid\right\}$ the energy-based damage index $D_{i}$ proposed by Darwin and Nmai [13] and the well-known index of damage $D I_{P A}$ developed by Park and Ang [14]. The results are shown in Table IV. The chord rotation demand $\theta_{m}$ was estimated from the measurements provided by displacement transducers during the tests. The chord rotation capacities at ultimate $\theta_{u}$ were predicted using the equation recommended by Eurocode 8 - Part 3 (Annex A) [15] based on the work by Fardis [16] and others. The damage index $D_{i}$, and the Park and Ang index of damage $D_{P A}$ at a given hinge $k$ were calculated by means of the following equations:

$$
\begin{gathered}
D_{i}=\frac{W_{p, k}}{0.5\left(M_{y}^{+} \theta_{y}^{+}+\left|M_{y}^{-}\right|\left|\theta_{y}^{-}\right|\right)} \\
D_{P A}=0.5\left[\frac{\theta_{m}^{+}-\theta_{y}^{+}}{\theta_{u}^{+}-\theta_{y}^{+}}+\frac{\left|\theta_{m}^{-}\right|-\left|\theta_{y}^{-}\right|}{\left|\theta_{u}^{-}\right|-\left|\theta_{y}^{-}\right|}\right]+\beta \frac{W_{p, k}}{0.5\left(M_{y}^{+} \theta_{u}^{+}+\left|M_{y}^{-}\right|\left|\theta_{u}^{-}\right|\right)}
\end{gathered}
$$

The chord rotation at yielding $\theta_{y}$ was also predicted with the equation recommended by Eurocode 8 - Part 3 (Annex A) [15]. The parameter $\beta$ was taken $\beta=0.1$. The yielding moments under positive and negative bending, $M_{y}^{+}$and $M_{y}^{-}$, were estimated with the following expressions for beams:

$$
M_{y}=0.9 h A_{t} f_{y}
$$

and for columns:

$$
\begin{aligned}
& \text { if } N_{\max }>N>\left(0.4 b h f_{c}\right): M_{y}=\frac{\left(0.8 A_{t} f_{y} h+0.12 b h^{2} f_{c}\right)\left(N_{\max }-N\right)}{N_{\max }-\left(0.4 b h f_{c}\right)} \\
& \text { if }\left(0.4 b h f_{c}\right)>N>0: \quad M_{y}=\left(0.8 A_{t} f_{y} h\right)+0.5 N h\left\{1-\left[N /\left(b h f_{c}\right)\right]\right\} \\
& \text { if } 0>N>N_{\text {min }}: \quad M_{y}=0.8 A_{t} f_{y} h+0.4 N h
\end{aligned}
$$




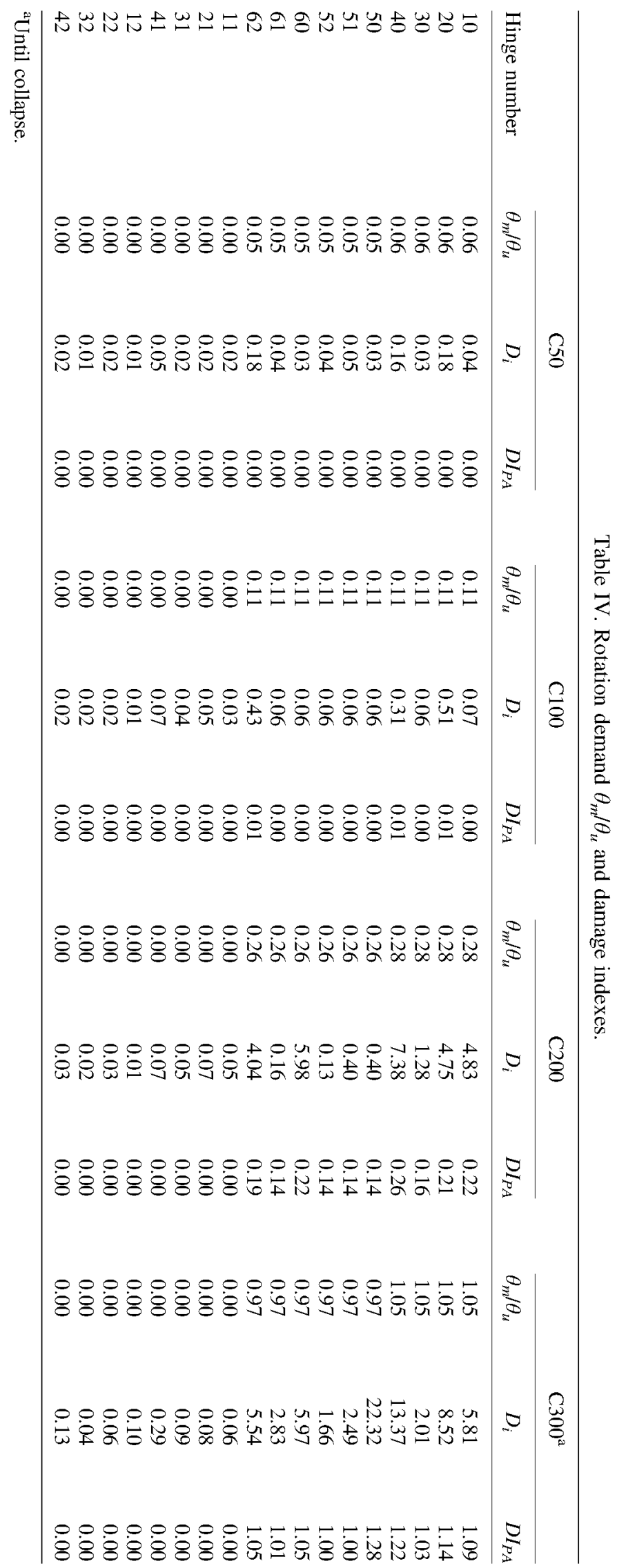


where $N$ is the axial force in the column (positive in compression); $N_{\max }=b h f_{c}+A_{g} f_{y} ; N_{\min }=-A_{g} f_{y} ; A_{t}$ is the area of longitudinal reinforcement in tension; $A_{g}$ is the total area of longitudinal reinforcement in the section; and $b, h$ are the base and depth of the section.

The damage in the plastic hinges was basically null for the seismic simulations C50 and C100. At the end of this simulation $\mathrm{C} 200$, the specimen experienced SD, attaining chord rotations of about one-fourth of the capacity at ultimate; the damage index $D_{i}$ reached 7.38 and the index of damage by Park and Ang $D I_{P A}$ reached 0.22. In general, damage was larger in the plastic hinges at the base of the columns than at beam ends. At the instant of collapse, during seismic simulation C300, the chord rotation demand reached the ultimate capacity with ratios $\theta_{m} / \theta_{u}$ very close to $\theta_{m} / \theta_{u}=1$; the damage index $D_{i}$ reached 22.32, and the damage index $D I_{P A}$ was about 1 . The pattern of larger damage at column bases than at beam end observed during simulation C200 remained at collapse. The following considerations must be made to interpret these results. First, the fact that the collapse of the hinges at column bases and at beam ends occurred for values of $\theta_{m} / \theta_{u}$ very close to 1 indicates that the formula recommended by Eurocode 8 - Part 3 for assessing chord rotation capacities at ultimate of RC beams, and columns subjected to cyclic loading produces very good estimates. Second, on the basis of extensive experimental studies, Darwin and Nmai [13] concluded that the range of $D_{i}$ for well-behaving RC beams was between 17 and 142; further, these authors recommended $D_{i}=35$ to provide adequate performance under cyclic loading. The RC beams tested in the shake-table sustained values of $D_{i}$ larger than 17 (i.e., 22.32) and can thus be classified as 'well-behaving beams', but the values are lower than the one recommended by these authors (35). Third, the results of the shake-table test indicate that the use of ultimate chord rotation capacities $\theta_{u}$ estimated with Eurocode 8 - Part 3, using the factor $\beta=0.1$ (as suggested by Park et al. for nominal strength deterioration) to calculate the index $D_{P A}$ with Eq. (11), provides a very good estimate of the level of damage in the range $D_{P A}=0$ (no damage) to $D_{P A}=1$ (collapse).

\subsection{Beam-to-column strength ratio}

In order to assure the formation of a strong column-weak beam mechanism and reduce the likelihood of yielding in columns, seismic codes typically require that the sum of flexural strengths of columns framing into a joint be larger than the sum of flexural strengths of the beams framing to the same joint. The amount by which the strength of the columns must exceed that of the beam varies depending on the code. ACI-318-08 [17] requires $\sum M_{n c} \geqslant 1.2 \sum M_{n b}$ and Eurocode 8 [4] $\sum M_{R c} \geqslant 1.3 \sum M_{R b}$. Here, $M_{n c}$ and $M_{n b}$ are the nominal flexural strengths of columns and beams, whereas $M_{R c}$ and $M_{R b}$ are the corresponding design values. In both cases, the bending moments $M_{n c}$, $M_{n b}, M_{R c}, M_{R b}$ must be evaluated at the faces of the joint. The last column of Table II shows the beam-to-column nominal moment strength ratios evaluated at the faces of the joints for the specimen tested. $M_{U c}$ and $M_{U b}$ were computed from nominal dimensions and the material strengths described in Section 2.2, in accordance with code definitions, provisions and assumptions of the strength design methods of ACI-318-08, the corresponding steel reinforcement for beams, and the corresponding steel reinforcement and axial load for columns. The ratios $\Sigma M_{U c} / \Sigma M_{U b}$ obtained are high due to the overstrength provided in columns at the design stage. In the case of interior joints, the ratio $\sum M_{U d} / \sum M_{U b}=2.09$ is clearly above the minimum required by ACI-318-08 and Eurocode 8 , but this fact did not prevent some plastic deformation from taking place in the longitudinal reinforcement of one of the columns (up to 1.4 times the yield strain).

\section{CONCLUSIONS}

Shake-table tests resulting in collapse were conducted on a two-fifths-scale RC frame structure designed according to current building seismic codes that follow the strong column-weak beam philosophy and capacity design criteria. The specimen was subjected to four seismic simulations representative of very frequent, frequent, rare and very rare earthquakes associated with return periods of 17, 97, 500 and 1435 years, respectively, in the Mediterranean area. The results of the tests lead us to put forth the following conclusions that are transferable to similar structures: 
- For the 'frequent earthquake', the specimen remained basically undamaged, with maximum interstory drifts of $0.5 \%$, Park and Ang's index of damage in the plastic hinges below 0.01 and maximum chord rotations below $11 \%$ of their ultimate capacity. The specimen performed on the boundary of the IO and LS seismic levels, that is, on the limit of what Eurocode 8 recommends.

- For the 'rare earthquake' (design earthquake), the specimen developed a strong column-weak beam mechanism and experienced SD. Maximum strains of longitudinal reinforcement in column bases and at beam ends reached about seven times the yield strain, the maximum inter-story drift was $1.19 \%$, and the maximum chord rotations reached $28 \%$ of their ultimate capacity. The seismic performance approached the upper bound of the LS level.

- The specimen collapsed at the beginning of the seismic simulation that represented the very rare event (maximum considered earthquake). Collapse was characterized by the opening of large flexural cracks of about $3 \mathrm{~mm}$ and simultaneous severe vertical sliding (of about $10 \mathrm{~mm}$ ) between the two sides of the crack. At this instant, the lateral drift exceeded 4\%, Park and Ang's index of damage in the plastic hinges was above 1 in all hinges (reaching 1.28 in one of them), and maximum chord rotations reached the ultimate rotation capacity. In general, the structure designed according to modern codes performed adequately (yet on the limit) for the SHLs corresponding to a frequent earthquake and to a 'design earthquake', but the performance was not satisfactory for the very rare or maximum considered earthquake.

- The test data when the specimen reached the point of collapse were compared with the formula recommended by Eurocode 8 (Part 3, informative Annex A). Comparison suggests that Eurocode 8 produces very good estimates on ultimate chord rotation capacities of RC beams and columns under cyclic loading.

- Park and Ang's damage index with $\beta=0.1$ was calculated at the instant of collapse for each plastic hinge, giving values very close to 1 . This corroborates that the Park and Ang index with $\beta=0.1$ is a good indicator of the level of damage on RC elements subjected to bending, in a range between 0 (no damage) and 1 (collapse).

This paper is funded by the Spanish Ministry of Science and Innovation with funding numbers BIA200800050 and BIA2011-26816, and the European Union (Fonds Européen de Dévelopment Régional). 